\title{
Outcomes of colorectal cancer surgery in nonagenarian patients: a multicenter retrospective study
}

\author{
Wei-Gen Zeng ${ }^{1}$, Meng-Jia Liu ${ }^{2}$, Zhi-Xiang Zhou ${ }^{3}$, Jun-Jie Hu ${ }^{4}$, Zhen-Jun Wang ${ }^{1}$ \\ ${ }^{1}$ Department of General Surgery, Beijing Chao-Yang Hospital, Capital Medical University, Beijing, China; ${ }^{2}$ Department of Ultrasound, Cancer \\ Hospital, Chinese Academy of Medical Sciences, Peking Union Medical College, Beijing, China; ${ }^{3}$ Department of Colorectal Surgery, Cancer \\ Hospital, Chinese Academy of Medical Sciences, Peking Union Medical College, Beijing, China; ${ }^{4}$ Department of Gastrointestinal Surgery, Hubei \\ Cancer Hospital, Wuhan, China \\ Contributions: (I) Conception and design: WG Zeng, ZJ Wang; (II) Administrative support: WG Zeng, MJ Liu, JJ Hu; (III) Provision of study \\ materials or patients: WG Zeng, ZX Zhou, MJ Liu, JJ Hu; (IV) Collection and assembly of data: WG Zeng, MJ Liu, ZX Zhou, JJ Hu; (V) Data \\ analysis and interpretation: WG Zeng, ZJ Wang; (VI) Manuscript writing: All authors; (VII) Final approval of manuscript: All authors. \\ Correspondence to: Prof. Zhen-Jun Wang, MD. Department of General Surgery, Beijing Chao-Yang Hospital, Capital Medical University, \\ No. 8 Gongtinan Road, Chaoyang District, Beijing 100020, China. Email: wzj_cyyy@163.com.
}

\begin{abstract}
Background: The use of surgery in patients with colorectal cancer (CRC) aged $\geq 90$ years remains controversial. This study aimed to evaluate the short-term postoperative and long-term oncologic outcomes of CRC surgery in patients within this age group.

Methods: A total of 151 consecutive nonagenarian patients who underwent CRC surgery were included from 3 different hospitals. The Comprehensive Complication Index (CCI) was used to grade postoperative complications. Univariate and multivariate analyses were conducted to identify factors associated with CCI and overall survival (OS).
\end{abstract}

Results: The patients had a mean age of 92.8 years (standard deviation \pm 1.9 years). Forty-six patients $(30.5 \%)$ underwent emergency surgery, and 105 patients $(69.5 \%)$ underwent elective surgery. The postoperative complications rate was $66.2 \%(100 / 151)$, and the mean CCI was $26.3( \pm 30.8)$. Twenty-three patients $(15.2 \%)$ died postoperatively, and the perioperative mortality rates for elective surgery and emergency surgery were 7.6\% (8/105) and 32.6\% (15/46), respectively $(\mathrm{P}<0.001)$. The 1-, 3-, and 5-year survival rates were $77.5 \%$, $53.9 \%$, and $38.6 \%$, respectively. Multivariate analysis revealed emergency surgery and American Society of Anesthesiologists (ASA) score to be predictors of postoperative complications. Advanced tumor stage, palliative surgery, ASA score $\geq 4$, and CCI $>17$ were associated with poor OS.

Conclusions: CRC surgery should not be denied to nonagenarian patients. Surgical treatment can be performed with acceptable morbidity and mortality, and achieves long-term survival in a select group.

Keywords: Colorectal cancer (CRC); nonagenarian; elderly; survival; mortality

Submitted May 27, 2021. Accepted for publication Jun 29, 2021.

doi: 10.21037/jgo-21-324

View this article at: https://dx.doi.org/10.21037/jgo-21-324

\section{Introduction}

Life expectancies are rising globally, and the number of people who reach the age of 90 and beyond is increasing. However, with age, the incidence of cancer increases. For instance, age is an important risk factor for colorectal cancer (CRC), which is the third most common cancer in the world $(1,2)$. Older people are increasingly being diagnosed with
CRC, with a median age at diagnosis of about 70 years (3). Further, in patients aged $\geq 90$ years, CRC accounts for more than one-fifth of new cancer diagnoses (4).

Surgical treatment remains the mainstay for resectable CRC. However, surgery is not always performed on nonagenarians with CRC due to the risk of complications relating to age, comorbidity, and reduced functional 
reserve. It has even been considered that the best treatment option for nonagenarians with CRC is no treatment (5). However, to date, data on the outcomes of CRC surgery in nonagenarians are limited.

The present study aimed to evaluate the short-term postoperative results and long-term survival following CRC surgery in patients aged $\geq 90$ years, and to define factors associated with the Comprehensive Complication Index (CCI) and overall survival (OS).

We present the following article in accordance with the STROBE reporting checklist (available at https://dx.doi. org/10.21037/jgo-21-324).

\section{Methods}

\section{Patients}

From January 2000 to December 2019, 151 consecutive patients with CRC aged $\geq 90$ years from 3 individual hospitals were enrolled. Patients were excluded if they did not undergo surgery, had CRC concurrent with another type of cancer, or had incomplete clinical records.

Before surgery, patients underwent a series of examinations, including: colonoscopy with biopsies, CT of the abdominal pelvic cavity, and chest X-ray or CT. For patients undergoing elective surgery, mechanical bowel preparation was administered 1 day before surgery. All patients were given intravenous antibiotics 30 minutes before surgery, and the antibiotics lasted for 48 hours after surgery.

Different surgical procedures were performed depending on the patient's tumor site, tumor stage, and condition. Surgical procedures performed within 24 hours after hospital admission were defined as emergency surgery. The surgical procedures have been described in detail previously $(6,7)$. For laparoscopic surgery, multiple trocars (4 or 5 trocars) were used.

Data on postoperative complications were collected, and the CCI was used to classify complications (8). Operative mortality was defined as any death related to surgery or surgical complications. Tumor specimens were examined by at least 2 pathologists. Tumors were staged according to the American Joint Committee on Cancer $\left(8^{\text {th }}\right.$ edition) staging system.

\section{Data collection}

The following patient data were prospectively collected: sex, age, Eastern Cooperative Oncology Group (ECOG) performance status score, body mass index (BMI), patient comorbidities, American Society of Anesthesiologists (ASA) score, tumor location, and tumor stage. Patient comorbidities were recorded and graded according to the Charlson Comorbidity Index (9). OS was defined as the time from the date of surgery to the date of death.

\section{Statistical analysis}

Quantitative variables were expressed as means and standard deviations (SDs), and the Student's $t$-test was used for comparisons. Categorical variables were expressed as frequencies and percentages, and comparisons were analyzed by the chi-square test, when one or more of the cell counts in a $2 \times 2$ table was less than 5 , Fisher's exact test was used. All comparisons were two-sided, and $\mathrm{P}<0.05$ was considered to indicate statistical significance.

Linear regression was adopted to analyze the clinicopathological factors associated with the CCI. The Kaplan-Meier method was employed to calculate survival, and the survival curves were compared by the log-rank test. The Cox proportional-hazards model was applied to analyze survival-associated factors, and adjusted hazard ratios (HRs) and their 95\% confidence intervals (CIs) were calculated. Variables with significant associations in univariate analysis, as defined by a $\mathrm{P}$ value $<0.1$, were included in multivariate analysis. SPSS 25.0 for Windows (IBM Corporation, Armonk, NY, USA) was used to perform the data analyses.

All procedures performed in this study involving human participants were in accordance with the Declaration of Helsinki (as revised in 2013). The study was approved by institutional ethics board of three hospitals (No.:2014ke-161-1). Individual consent for this retrospective analysis was waived.

\section{Results}

\section{Clinical factors}

This study included 151 patients with CRC aged $\geq 90$ years, among whom 89 patients (58.9\%) were women. The patients had a mean age of 92.8 years ( $\mathrm{SD} \pm 1.9$ years), and their mean Charlson Comorbidity Index score was $7.7( \pm 2.6)$. Colon cancer was more common than rectal cancer $(66.9 \%$ vs. $33.1 \%$, Table 1).

There were 105 cases $(69.5 \%)$ and 46 cases $(30.5 \%)$ of elective surgery and emergency surgery, respectively. 
Table 1 General features of nonagenarian patients who received colorectal cancer surgery

\begin{tabular}{|c|c|c|c|c|}
\hline Characteristic & Total $(n=151)$ & Emergency surgery $(n=46)$ & Elective surgery $(n=105)$ & $P$ value \\
\hline Age (years) & $92.8( \pm 1.9)$ & $92.6( \pm 2.2)$ & $92.9( \pm 1.8)$ & 0.350 \\
\hline BMI & $21.5( \pm 3.0)$ & $20.8( \pm 2.7)$ & $21.9( \pm 3.0)$ & 0.051 \\
\hline Tumor location (\%) & & & & 0.002 \\
\hline Rectum & $50(33.1)$ & $7(15.2)$ & $43(41.0)$ & \\
\hline ECOG score (\%) & & & & 0.517 \\
\hline 2 & $44(29.1)$ & $11(23.9)$ & $33(31.4)$ & \\
\hline 3 & $88(58.3)$ & $30(65.2)$ & $58(55.2)$ & \\
\hline 2 & $49(32.5)$ & $13(28.3)$ & $36(34.3)$ & \\
\hline 3 & $86(57.0)$ & $26(56.5)$ & $60(57.1)$ & \\
\hline 4 & $16(10.6)$ & $7(15.2)$ & $9(8.6)$ & \\
\hline Tumor stage (\%) & & & & 0.004 \\
\hline 1 & $12(7.9)$ & $0(0.0)$ & $12(11.4)$ & \\
\hline 2 & $59(39.1)$ & $13(28.3)$ & $46(43.8)$ & \\
\hline 3 & $69(45.7)$ & $28(60.9)$ & $41(39.0)$ & \\
\hline 4 & $11(7.3)$ & 5 (10.9) & $6(5.7)$ & \\
\hline Open & $110(72.8)$ & $44(95.7)$ & $66(62.9)$ & \\
\hline Surgical intent (\%) & & & & 0.141 \\
\hline Curative & $128(84.8)$ & $36(78.3)$ & $92(87.6)$ & \\
\hline Palliative & $23(15.2)$ & $10(21.7)$ & $13(12.4)$ & \\
\hline Operative procedure (\%) & & & & 0.025 \\
\hline Right/extended right colectomy & $54(35.8)$ & $19(41.3)$ & 35 (33.3) & \\
\hline Hartmann's procedure & $25(16.6)$ & $8(17.4)$ & $17(16.2)$ & \\
\hline Left hemicolectomy/sigmoidectomy & $24(15.9)$ & $10(21.7)$ & $14(13.3)$ & \\
\hline Anterior resection & $21(13.9)$ & $1(2.2)$ & $20(19.0)$ & \\
\hline Trans-anal excision & $3(2.0)$ & $0(0.0)$ & $3(2.9)$ & \\
\hline Subtotal colectomy & $5(3.3)$ & $0(0.0)$ & $5(4.8)$ & \\
\hline
\end{tabular}

Table 1 (continued) 
Table 1 (continued)

\begin{tabular}{|c|c|c|c|c|}
\hline Characteristic & Total $(n=151)$ & Emergency surgery $(n=46)$ & Elective surgery $(n=105)$ & $P$ value \\
\hline Postoperative complications (\%) & $100(66.2)$ & $40(87.0)$ & $60(57.1)$ & $<0.001$ \\
\hline $\mathrm{CCl}$ & $26.3( \pm 30.8)$ & $39.7( \pm 35.1)$ & $20.4( \pm 26.8)$ & $<0.001$ \\
\hline Postoperative hospital stay (days) & $17.0( \pm 11.8)$ & $20.9( \pm 16.4)$ & $15.3( \pm 8.7)$ & 0.007 \\
\hline Operative mortality (\%) & $23(15.2)$ & $15(32.6)$ & $8(7.6)$ & $<0.001$ \\
\hline
\end{tabular}

BMI, body mass index; ECOG, Eastern Cooperative Oncology Group; ASA, American Society of Anesthesiologists; CCI, Comprehensive Complication Index.

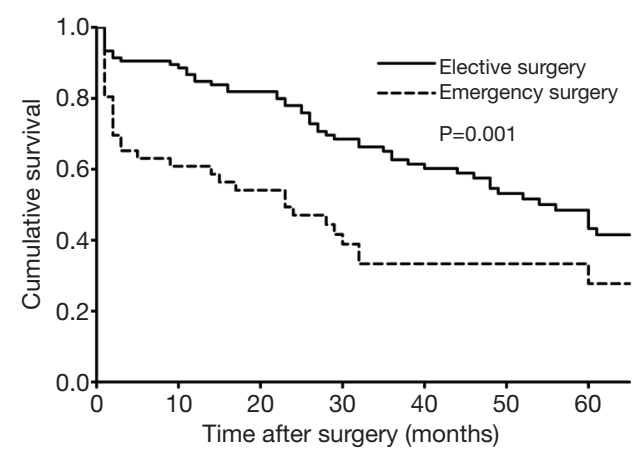

Figure 1 Cumulative survival after elective and emergency surgery.

Most patients underwent open resection (72.8\%), which was performed with curative intent in $84.8 \%$ of such cases. The most common surgical procedures included right colectomy (35.8\%), Hartmann's procedure (16.6\%), left hemicolectomy/sigmoidectomy (15.9\%), and anterior resection $(13.9 \%)$. Primary anastomosis was performed in 95 patients $(62.9 \%)$.

\section{Operative outcomes}

The postoperative complications rate was $66.2 \%$. The median CCI was 17.3 (range, 0-100), and the mean CCI was $26.3( \pm 30.8)$. The most frequently observed complications were confusion (23.8\%), pneumonia (22.5\%), ileus (19.2\%), and renal failure (17.2\%). Two patients (2.1\%) experienced anastomotic leakage, both of whom underwent emergency surgery (1 right colectomy and 1 left hemicolectomy).

A total of 23 patients (15.2\%) died postoperatively, from causes including pneumonia or respiratory failure $(n=9)$, sepsis $(\mathrm{n}=5)$, stroke $(\mathrm{n}=3)$, acute myocardial infarction $(\mathrm{n}=3)$, multiple organ failure $(n=2)$, and intracranial hemorrhage $(n=1)$.
Patients who underwent emergency surgery and those who underwent elective surgery displayed significant differences in demographics and operative outcomes. Significant differences were detected in tumor site $(\mathrm{P}=0.002)$, tumor stage $(\mathrm{P}=0.004)$, Charlson Comorbidity Index (8.4 vs. 7.4, $\mathrm{P}=0.048)$, surgical approach $(\mathrm{P}<0.001)$, surgical procedure $(\mathrm{P}=0.025)$, postoperative complications (87.0\% vs. 57.1\%, $\mathrm{P}<0.001$ ), CCI (39.7 vs. 20.4, $\mathrm{P}<0.001$ ), postoperative hospital stay (20.9 days vs. 15.3 days, $\mathrm{P}=0.007)$, and operative mortality $(32.6 \%$ vs. $7.6 \%$, $\mathrm{P}<0.001)$ between the emergency surgery group and elective surgery group.

\section{Oncologic outcomes}

The median follow-up was 30 months (range, 1-106 months). The 1-, 3-, and 5-year survival rates were $77.5 \%, 53.9 \%$, and $38.6 \%$, respectively. The estimated 5 -year OS rate was $43.3 \%$ (95\% CI, 32.1-54.5) in the elective surgery group, and $27.8 \%(95 \% \mathrm{CI}, 12.1-43.5)$ in the emergency surgery group (Figure 1, $\mathrm{P}=0.001$ ).

\section{Univariate and multivariate analysis}

In univariate analysis, ASA score $(\mathrm{P}<0.001)$, ECOG score $(\mathrm{P}=0.002)$, emergency surgery $(\mathrm{P}<0.001)$, and open surgery $(\mathrm{P}=0.059)$, were significantly associated with CCI (Table 2$)$. In multivariate analysis with a linear regression model, only ASA score $(\mathrm{P}<0.001)$ and emergency surgery $(\mathrm{P}=0.004)$ retained their significance as independent prognostic factors for postoperative complications.

Univariate analysis showed that palliative surgery $(\mathrm{P}<0.001)$, advanced tumor stage $(\mathrm{P}=0.001)$, ASA score $\geq 4$ $(\mathrm{P}<0.001)$, ECOG score $\geq 4(\mathrm{P}=0.027)$, emergency surgery 
Table 2 Univariate and multivariate analyses of the effects of covariates on Comprehensive Complications Index

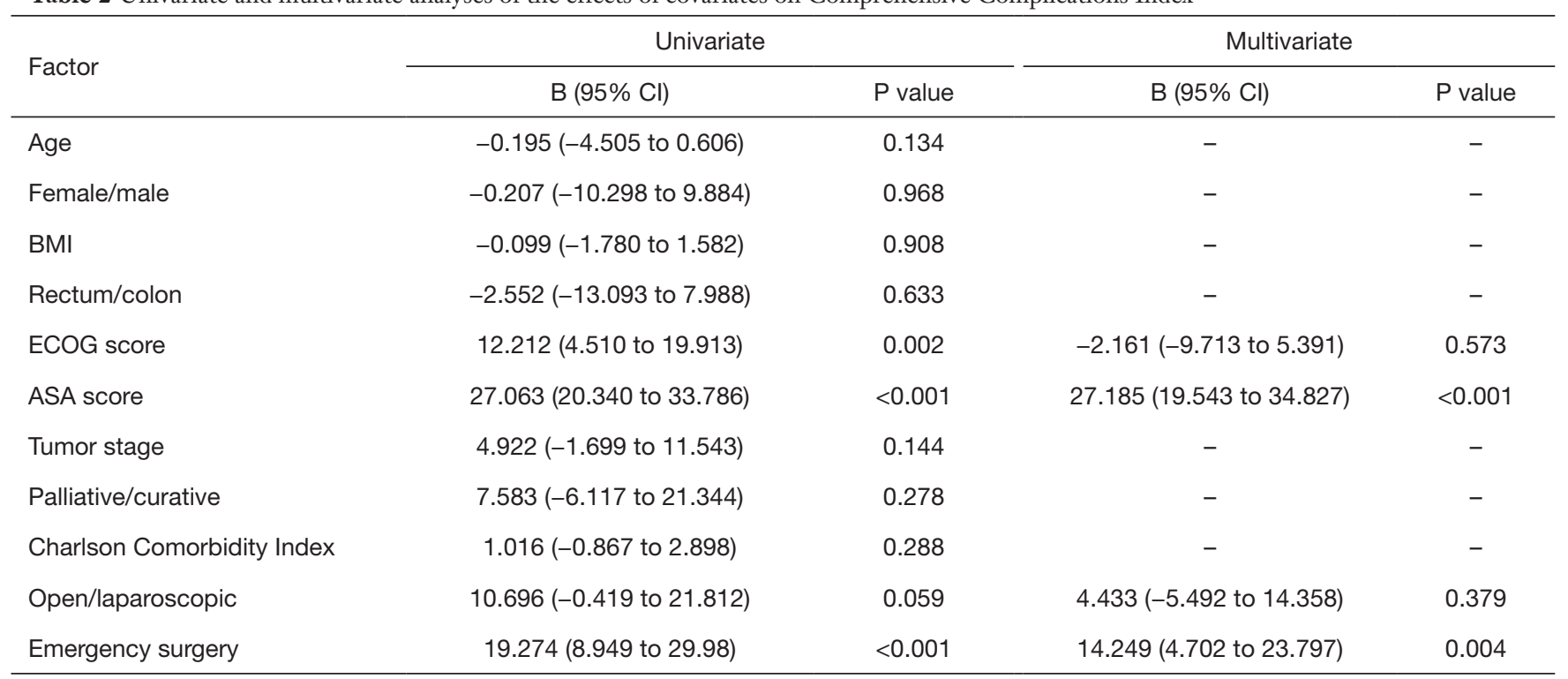

B, regression coefficient; $\mathrm{Cl}$, confidence interval; BMI, body mass index; ECOG, Eastern Cooperative Oncology Group.

$(\mathrm{P}=0.002)$, and $\mathrm{CCI}>17(\mathrm{P}=0.001)$ were significantly associated with poor survival (Table 3). Multivariate analysis identified advanced tumor stage $(\mathrm{HR}=2.024 ; 95 \% \mathrm{CI}, 1.254$ 3.268; $\mathrm{P}=0.004)$, palliative surgery $(\mathrm{HR}=1.876 ; 95 \% \mathrm{CI}$, 1.011-3.481; $\mathrm{P}=0.046$ ), ASA score $\geq 4$ ( $\mathrm{HR}=2.638 ; 95 \% \mathrm{CI}$, 1.132-6.148; $\mathrm{P}=0.025)$, and $\mathrm{CCI}>17$ (HR $=1.784 ; 95 \% \mathrm{CI}$, $1.127-2.823 ; \mathrm{P}=0.013)$ as factors associated with poor OS.

\section{Discussion}

Data on the operative and oncologic outcomes of nonagenarians with CRC are scarce. Several retrospective studies with a small number of patients have reported that CRC surgery appeared to be safe for select patients aged $\geq 90$ years, with acceptable morbidity and mortality, although the results were conflicting (10-15). Therefore, we conducted a multicenter study with a larger number of patients aged $\geq 90$ years, and investigated their operative and oncologic outcomes.

In the present study, $66.2 \%$ patients experienced some type of complication; however, the median CCI was 17.3, and many of the complications were minor. Although the overall operative mortality rate was relatively high $(15.2 \%)$, the mortality rate of elective surgery was lower, at $7.6 \%$, which is similar to the results reported by other authors $(8-10,13)$. The 5 -year survival rate was $38.6 \%$. Based on our results, we believe that surgical treatment can achieve acceptable short-term postoperative and long-term oncologic outcomes for patients with CRC aged $\geq 90$ years; therefore, it should not be denied to this population.

We found that pneumonia or respiratory failure was the first cause of death. Chan et al. (11) also demonstrated that pneumonia with respiratory failure as the most common postoperative complication and the leading cause of mortality. Yap et al. (14) reported that by incorporating a physician's input into the perioperative care, the 30-day mortality could be as low as $2.1 \%$, patients in the study had a much lower (2\%) incidence of pneumonia. These encouraging results demonstrated the importance of multidisciplinary collaborative care in the extreme elderly.

Emergency surgery was found to be an independent risk factor for complications among the patients in our study, and the rate of operative mortality was high $(32.6 \%)$ in patients who underwent emergency resection. Therefore, it is reasonable to avoid urgent surgery and to offer therapeutic alternatives, such as self-expanding metallic stents for patients with colonic obstructions (16). Turning emergency surgery into elective surgery would aid in decreasing morbidity and mortality. For the inevitable emergency operation, multidisciplinary collaborative care was of great important. More attention should be paid to their breathing, because respiratory failure was the first cause of death.

In contrast, laparoscopic surgery was found to be 
Table 3 Univariate and multivariate analysis of the effects of covariates on survival

\begin{tabular}{|c|c|c|c|c|}
\hline Factor & \multicolumn{2}{|c|}{ Univariate } & \multicolumn{2}{|c|}{ Multivariate } \\
\hline Age & $0.941(0.839-1.055)$ & 0.291 & - & - \\
\hline \multicolumn{5}{|l|}{ Sex } \\
\hline Male & Reference & & & \\
\hline BMI & $1.018(0.951-1.089)$ & 0.616 & - & - \\
\hline \multicolumn{5}{|l|}{ Tumor location } \\
\hline Colon & Reference & & & \\
\hline Rectum & $0.830(0.534-1.288)$ & 0.406 & - & - \\
\hline Palliative & 3.165 (1.789-5.599) & $<0.001$ & $1.876(1.011-3.481)$ & 0.046 \\
\hline \multicolumn{5}{|l|}{ ASA score } \\
\hline$<4$ & Reference & & Reference & \\
\hline$\geq 4$ & $3.318(1.849-5.956)$ & $<0.001$ & $2.638(1.132-6.148)$ & 0.025 \\
\hline \multicolumn{5}{|l|}{ ECOG score } \\
\hline$<4$ & Reference & & Reference & \\
\hline$\geq 4$ & $1.874(1.073-3.273)$ & 0.027 & $0.869(0.403-1.872)$ & 0.720 \\
\hline \multicolumn{5}{|l|}{ Stage } \\
\hline \multicolumn{5}{|c|}{ Surgical approach } \\
\hline Laparoscopic & Reference & & & \\
\hline Open & $1.172(0.722-1.902)$ & 0.521 & - & - \\
\hline \multicolumn{5}{|l|}{$\mathrm{CCl}$} \\
\hline$\leq 17$ & Reference & & Reference & \\
\hline$>17$ & $1.962(1.301-2.959)$ & 0.001 & $1.784(1.127-2.823)$ & 0.013 \\
\hline Chemotherapy & $0.989(0.524-1.866)$ & 0.989 & - & - \\
\hline \multicolumn{5}{|l|}{ Type of surgery } \\
\hline Elective & Reference & & & \\
\hline Emergency & $2.033(1.310-3.156)$ & 0.002 & 1.545 (0.963-2.478) & 0.071 \\
\hline
\end{tabular}

HR, hazard ratio; Cl, confidence interval; BMI, body mass index; ASA, American Society of Anesthesiologists; ECOG, Eastern Cooperative Oncology Group; CCI, Comprehensive Complication Index. 
associated with a low risk of postoperative complications in univariate analysis, although its statistical significance was lost in multivariate analysis. The benefits of laparoscopic colorectal resection have been widely studied in randomized controlled trials (17-20). However, all of these trials excluded elderly patients. Elderly patients are associated with higher rate of comorbidities and reduced functional reserve compared with younger patients, and increasing age itself is an important risk factor for postoperative morbidity and mortality. The usage of laparoscopic surgery in the very elderly patient remains controversial, the haemodynamic changes secondary to the increased intra-abdominal pressure caused by the pneumoperitoneum can be associated with perioperative complications which may be most marked in the nonagenarians. Because of safety considerations, most patients underwent open resection (72.8\%). However, we found that laparoscopic surgery could be performed safely in nonagenarians and was associated with a low rate of complications. Laparoscopic surgery might be a better choice for colorectal cancer patients over 90 years old, especially for patients with palliative surgery. Further studies with larger sample sizes are needed to confirm these results.

Few studies have reported on the risk of anastomotic leakage in nonagenarians. In the present study, the rate of anastomotic leakage was low, with only 2 patients $(2.1 \%)$ developing this complication. This observation is consistent with those of other authors. For instance, Roque-Castellano et al. (10) performed 18 anastomoses, with no cases of leakage reported, and Yap et al. (14) reported only 1 case of anastomotic leakage after right hemicolectomy. On the basis of these results, anastomosis should not be denied to patients aged $\geq 90$ years.

ASA score was identified as an independent risk factor for both postoperative complications and survival. Surgeons should be extremely cautious in deciding whether to perform surgery on patients with an ASA score of $\geq 4$, due to the association with a poor prognosis following surgery. Higher disease stages and palliative surgery were also associated with poor OS, indicating that the biological behavior of tumors is similar between nonagenarians and younger patients. However, for nonagenarian patients with an ASA score $<4$, curative surgery should be considered, especially for those in the early stages of cancer.

In most previous studies, postoperative morbidity was assessed using the Clavien-Dindo classification, which grades the severity of postoperative complications according to the most severe complication when the patient has more than 1 complication (21). The CCI is a novel metric of postoperative complications. It shows an improvement on the CDC because it is calculated as the sum of all complications and is connected to clinical outcomes $(8,22)$. Previously, only one study had used the CCI to evaluate postoperative complications in patients with CRC aged $\geq 90$ years. Roque-Castellano et al. (10) found that the mean CCI score was 28.7 and that the mortality rate reached $100 \%$ in patients with a CCI score $\geq 60$. We also found that CCI was an independent prognostic factor for OS. These results demonstrate that CCI should be used to assess postoperative complications and survival in patients with CRC aged $\geq 90$ years.

Although this is a multicenter study involving a larger number of patients than previous studies, it still has some limitations. Firstly, owing to the study's retrospective nature, potential bias may exist. Secondly, the patients who received surgery were regarded as having a low risk of complications. Thirdly, data on patients who did not receive surgery were not available. Finally, we only reported the results of morbidity and mortality, as information about the patients' quality of life and functional outcomes was not available.

\section{Conclusions}

CRC surgery should not be denied to nonagenarian patients. Surgical treatment can be performed with acceptable morbidity and mortality, and achieves long-term survival in a select group (e.g., elective surgery, ASA score $<4$, early-stage cancer) of these patients.

\section{Acknowledgments}

Funding: None.

\section{Footnote}

Reporting Checklist: The authors have completed the STROBE reporting checklist. Available at https://dx.doi. org/10.21037/jgo-21-324

Data Sharing Statement: Available at https://dx.doi. org/10.21037/jgo-21-324

Conflicts of Interest: All authors have completed the ICMJE uniform disclosure form (available at https://dx.doi. org/10.21037/jgo-21-324). The authors have no conflicts of 
interest to declare.

Ethical Statement: The authors are accountable for all aspects of the work in ensuring that questions related to the accuracy or integrity of any part of the work are appropriately investigated and resolved. All procedures performed in this study involving human participants were in accordance with the Declaration of Helsinki (as revised in 2013). The study was approved by institutional ethics board of three hospitals (No.:2014-ke-161-1). Individual consent for this retrospective analysis was waived.

Open Access Statement: This is an Open Access article distributed in accordance with the Creative Commons Attribution-NonCommercial-NoDerivs 4.0 International License (CC BY-NC-ND 4.0), which permits the noncommercial replication and distribution of the article with the strict proviso that no changes or edits are made and the original work is properly cited (including links to both the formal publication through the relevant DOI and the license). See: https://creativecommons.org/licenses/by-nc-nd/4.0/.

\section{References}

1. Torre LA, Bray F, Siegel RL, et al. Global cancer statistics, 2012. CA Cancer J Clin 2015;65:87-108.

2. Kunitake H, Zingmond DS, Ryoo J, et al. Caring for octogenarian and nonagenarian patients with colorectal cancer: what should our standards and expectations be? Dis Colon Rectum 2010;53:735-43.

3. Kordatou Z, Kountourakis P, Papamichael D. Treatment of older patients with colorectal cancer: a perspective review. Ther Adv Med Oncol 2014;6:128-40.

4. Saltzstein SL, Behling CA, Baergen RN. Features of cancer in nonagenarians and centenarians. J Am Geriatr Soc 1998;46:994-8.

5. Kitagawa T, Hara M, Sano T, et al. The concept of Tenjugann, or "natural-end cancer". Cancer 1998;83:1061-5.

6. Zeng WG, Liu MJ, Zhou ZX et al. Outcome of Laparoscopic Versus Open Resection for Transverse Colon Cancer. J Gastrointest Surg 2015;19:1869-74.

7. Zeng WG, Liu MJ, Zhou ZX, et al. Impact of previous abdominal surgery on the outcome of laparoscopic resection for colorectal cancer: a case-control study in 756 patients. J Surg Res 2015;199:345-50.

8. Slankamenac K, Graf R, Barkun J, et al. The comprehensive complication index: a novel continuous scale to measure surgical morbidity. Ann Surg
2013;258:1-7.

9. Charlson ME, Pompei P, Ales KL, et al. A new method of classifying prognostic comorbidity in longitudinal studies: development and validation. J Chronic Dis 1987;40:373-83.

10. Roque-Castellano C, Fariña-Castro R, NoguésRamia EM, et al. Colorectal cancer surgery in selected nonagenarians is relatively safe and it is associated with a good long-term survival: an observational study. World J Surg Oncol 2020;18:120.

11. Chan TY, Foo CC, Law WL, et al. Outcomes of colorectal cancer surgery in the nonagenarians: 20-year result from a tertiary center. BMC Surg 2019;19:155.

12. Chen TC, Liang JT, Chang TC. Should Surgical Treatment Be Provided to Patients with Colorectal Cancer Who Are Aged 90 Years or Older? J Gastrointest Surg 2018;22:1958-67.

13. Au S, Ventham NT, Yalamarthi S, et al. Colorectal cancer outcomes in nonagenarian patients: A case series. Int J Surg 2018;5 5:139-44.

14. Yap R, Oliva K, Wilkins S, et al. Colorectal Cancer Surgery in the Very Elderly: Nonagenarians. Dis Colon Rectum 2016;59:501-7.

15. Arenal JJ, Tinoco C, Labarga F, et al. Colorectal cancer in nonagenarians. Colorectal Dis 2012;14:44-7.

16. Spannenburg L, Sanchez Gonzalez M, Brooks A, et al. Surgical outcomes of colonic stents as a bridge to surgery versus emergency surgery for malignant colorectal obstruction: A systematic review and meta-analysis of high quality prospective and randomised controlled trials. Eur J Surg Oncol 2020;46:1404-14.

17. Buunen M, Veldkamp R, Hop WC, et al. Survival after laparoscopic surgery versus open surgery for colon cancer: long-term outcome of a randomised clinical trial. Lancet Oncol 2009; 10:44-52.

18. Nelson H, Sargent DJ, Wieand HS, et al. A comparison of laparoscopically assisted and open colectomy for colon cancer. N Engl J Med 2004;350:2050-9.

19. Kang SB, Park JW, Jeong SY, et al. Open versus laparoscopic surgery for mid or low rectal cancer after neoadjuvant chemoradiotherapy (COREAN trial): shortterm outcomes of an open-label randomised controlled trial. Lancet Oncol 2010;11:637-45.

20. van der Pas MH, Haglind E, Cuesta MA, et al. Laparoscopic versus open surgery for rectal cancer (COLOR II): short-term outcomes of a randomised, phase 3 trial. Lancet Oncol 2013;14:210-8.

21. de la Plaza Llamas R, Ramia Ángel JM, Bellón JM, et al. 
Clinical Validation of the Comprehensive Complication Index as a Measure of Postoperative Morbidity at a Surgical Department: A Prospective Study. Ann Surg 2018;268:838-44.

22. Clavien PA, Vetter D, Staiger RD, et al. The
Comprehensive Complication Index (CCI®): Added Value and Clinical Perspectives 3 Years "Down the Line". Ann Surg 2017;265:1045-50.

(English Language Editor: J. Reynolds)

Cite this article as: Zeng WG, Liu MJ, Zhou ZX, Hu JJ, Wang ZJ. Outcomes of colorectal cancer surgery in nonagenarian patients: a multicenter retrospective study. J Gastrointest Oncol 2021;12(4):1568-1576. doi: 10.21037/jgo-21324 